\title{
Usefulness of clinical observations and blood chemistry values for predicting clinical outcomes in dairy goats with pregnancy toxaemia
}

\author{
Miguel S. Lima ${ }^{1 *}$, Júlia M. Silveira', Nuno Carolino², Luis P. Lamas ${ }^{1}$, Rita A. Pascoal ${ }^{3}$ and Charles A. Hjerpe ${ }^{4}$
}

\begin{abstract}
Background: Pregnancy toxaemia (PT) is a disease that affects pregnant goats during their last month of gestation and is characterized by a high case fatality rate. This study involved 32 does maintained on a commercial dairy goat farm that were diagnosed with PT. A physical examination was performed on and haematology parameters obtained from each doe, at the time of diagnosis. The data from the 24 PT goats that died was compared with the corresponding data from the 8 PT goats that survived.

Results: Polypnea, swollen limbs, anorexia with absence of ruminal motility, recumbency, nervous signs and drooping ears were the most frequently observed clinical manifestations. Nineteen out of 21 recumbent goats died. Sixteen out of 17 goats with anorexia and absence of ruminal motility died. Mean beta-hydroxybutyric acid (BHBA) values in the goats that died were not significantly different from those in goats that survived. The blood values for $\mathrm{pH}$ and $\mathrm{pCO}_{2}(p<0.005)$ as well as for $\mathrm{HCO}_{3}^{-}, \mathrm{BE}$ and $\mathrm{K}^{+}(p<0.001)$ were significantly lower in the goats that died than in those that survived.

Conclusions: The clinical signs most indicative of a poor prognosis are anorexia with absence of ruminal motility and recumbency. Among the blood parameters to be considered, hypokalaemia and metabolic acidosis are the most relevant. Goats with PT have a high mortality and their condition can deteriorate very fast. Based on the authors's experience, a good strategy to minimize the economic losses caused by PT is to focus on the offspring survival rate since an early decision (induction of kidding or caesarian surgery) can increase the number of alive kids.
\end{abstract}

Keywords: Pregnancy toxaemia, Goats, Clinical signs, Metabolic acidosis, Hypokalaemia, Prognosis

\section{Background}

Pregnancy toxaemia in small ruminants is a metabolic disease that occurs in pregnant ewes or does, it is caused by negative energy balance and is nearly always associated with rapid growth of multiple foetuses during late gestation $[1,2]$. The clinical signs most consistently found are anorexia, ruminal atony, polypnea, drooping ears, a preference for recumbency with reluctance to stand or walk, inability to stand or walk and swelling (subcutaneous edema) of the limbs [1-4]. Less frequently present are

\footnotetext{
* Correspondence: mlmslima@fmv.ulisboa.pt

${ }^{1}$ Faculdade de Medicina Veterinária, Centro de Investigação Interdisciplinar em Sanidade Animal (CIISA), DC, Universidade de Lisboa, Polo Universitário da Ajuda, Lisbon 1300-477, Portugal

Full list of author information is available at the end of the article
}

nervous signs such as "star gazing", incoordination, and muscle tremors [1-4]. The major blood chemistry alterations observed in PT goats are increased values of BHBA, hypoglycaemia, hypokalaemia and a marked metabolic acidosis [1-4]. Other metabolic abnormalities may include hypocalcaemia, hypophosphataemia and increased activities of hepatic enzymes in blood serum [5].

Previous studies [5] have shown high case fatality rates in goats affected by PT exceeding $80 \%$ in untreated animals. A different study [4] has shown the case fatality rate to be $86 \%$ (19 of 22) even when kidding was induced or a caesarian surgery was performed and medical treatments (fluids, electrolytes, glucose and propylene glycol) were vigorously administered. Considering 
this high rate of mortality of goats affected with PT, in this study we have used offspring survival rate when different clinical options are taken as an outcome measure. We hypothesized that the latter would vary depending on clinical signs and clinical pathology parameters of the dam as this focus seems to be a more useful strategy to minimize economical losses.

As the onset of clinical signs in PT affected animals is often difficult to identify due to its subtlety, the course of the disease may progress rapidly after the diagnosis is established. Therefore, clinical decisions regarding treatment and management must be made and implemented rapidly. In a previous study [4], it was found that $58 \%$ (11 of 19) of the PT does died within $24 \mathrm{~h}$ after the clinical signs were first observed, and only one lived longer than 3 days. This implies that treatment must be initiated early in the course of the disease, or it will nearly always be unsuccessful $[1,2,4,6]$. The first decision to be made is whether to simply (1) to attempt to treat the patient, (a) by administering supportive treatments in the interest of addressing the metabolic abnormalities that are present (especially metabolic acidosis, hypokalaemia, and hypoglycaemia) and (b) by terminating the pregnancy or (2) euthanize the patient,. If a decision is made to attempt to treat the patient, the next decision to be made will be selecting the method used for terminating the pregnancy. The two available choices are (1) caesarian surgery or (2) pharmaceutical induction of lambing/kidding. There appears to be an unreported but generalized opinion amongst the veterinary medical profession that caesarian surgery is the best option for saving the life of the dam and kids. However, the cost of this option is higher for the owner than the cost of pharmaceutical induction of parturition.

The clinical signs that have been most frequently found to be associated with a poor prognosis by other authors are (1) recumbency (lateral is more adverse than sternal), (2) drooping ears, and (3) neurologic signs (especially opisthotonus or "star gazing", incoordination, and muscle tremors) [1-5].

Certain blood parameters have been used as possible prognostic indicators in sheep with $\mathrm{PT}$, including fructosamine [7], alkaline phosphatase [8], BHBA [9] and pH [4]. In a previous study with 22 goats [4], it was shown that blood $\mathrm{pH}$ was the best available clinical pathology prognostic indicator: when the blood $\mathrm{pH}$ of the dam was below 7.12, the case fatality rate was $100 \%$. In these cases, euthanasia (or possibly, caesarian surgery) could have been indicated. When the $\mathrm{pH}$ was between 7.12 and 7.20, caesarian surgery was performed as soon as possible. Based on what is presently known, when the blood $\mathrm{pH}$ is above 7.20 , caesarean section appears to have little advantage over pharmacologic induction of kidding, with respect to the survival rates likely to be obtained, and would be expected to be more cost- effective than surgery. These recommendations are based on experiences with a relatively limited number of cases, and are subject to future revisions, as more case studies become available for analysis [4].

The objective of the present study was to establish a prognosis for dairy goats diagnosed with $\mathrm{PT}$, utilizing the blood values for $\mathrm{pH}, \mathrm{BHBA}$, glucose, ions $\left(\mathrm{K}^{+}, \mathrm{Na}^{+}, \mathrm{Cl}^{-}\right)$, blood gases and clinical signs. It was our intention that these data would enable the construction of a decisionmaking tree that would allow a more accurate identification which cases should be treated by caesarian surgery, and which can be treated adequately with more conservative and less expensive pharmaceutical methods for terminating pregnancy. As far as we are aware this is the first study that tries to establish a prognosis for PT does based on clinical signs and on haematological parameters, furthermore we provide valuable information on the realistic treatment goals and objectives.

\section{Methods \\ Herd characterization}

This study was performed on a 1,800-head dairy goat farm, located $40 \mathrm{~km}$ northeast of Lisbon, Portugal. The goats were of two breeds: Alpine (approximately 800 animals) and Saanen (approximately 800 animals), with some animals being crosses of these two breeds (approximately 200 animals). All goats were continuously housed in confinement and all adult lactating does had access to free stalls. There were three kidding seasons per year, beginning in January, April and October. Each kidding season began on the first day of the month, and continued for 45 days. Daily milk production in this herd averaged approximately $3 \mathrm{~L} /$ doe. Machine milking was performed twice daily.

\section{Feeding and herd management}

The lactating goats were offered a total mixed ration (TMR) consisting of corn silage, alfalfa hay, brewer's grains, rye-grass hay and a concentrate mix, fed ad libitum. The percentage of the elements of the TMR varied accordingly to the production level of the goats [high-producing goats ( $>3 \mathrm{~L}$ ), low-production goats $(<3 \mathrm{~L})$ ] (Table 1$)$.

The TMR was distributed once daily. All the adult goats had free access to mineral blocks containing salt, magnesium and trace amounts of iron, iodine, cobalt, manganese, zinc and selenium, in appropriate quantities.

One month before kidding, does producing less than $0.5 \mathrm{~L}$ of milk/day were moved to a separate pen (with other dry goats), milking was ceased, the TMR was withdrawn, and wheat straw was fed, ad libitum. In addition, $1 \mathrm{~kg} /$ head/day of a different concentrate mix was provided, split into 4 feedings, equally distributed throughout each $24-\mathrm{h}$ period (Table 2). The goats producing more than $0.5 \mathrm{~L}$ of mild /day remained in the low production (lactating) goat group and sometimes kidded while still lactating. 
Table 1 Proximate analyses of and dry matter intakes obtained with three rations fed to lactating and dry dairy goats

\begin{tabular}{llll}
\hline Nutrient & $\begin{array}{l}\text { High Producing } \\
\text { Does }\end{array}$ & $\begin{array}{l}\text { Low Producing } \\
\text { Does }\end{array}$ & Dry Does \\
\hline Dry Matter Intake (Kg/day) & $2.40-3.00$ & $1.80-2.00$ & $1.40-1.50$ \\
Dry Matter (\%) & Max: 50 & Max: 50 & $80-90$ \\
Crude Protein (\% of DM) & $17-18$ & $16-17$ & 12 \\
Crude Fat (\% of DM) & 5 & 5 & 4 \\
Crude Fiber (\% of DM) & 16 & 17 & 17 \\
$\begin{array}{l}\text { Acid Detergent Fiber } \\
\text { (\% of DM) }\end{array}$ & 19 & 20 & 21 \\
$\begin{array}{l}\text { Neutral Detergent Fiber } \\
\text { (\% of DM) }\end{array}$ & 28 & 30 & 31 \\
Starch (\% of DM) & $15-18$ & $12-14$ & $10-15$ \\
Ca (\% of DM) & $0.80-0.90$ & $0.75-0.80$ & 0.35 \\
P (\% of DM) & $0.40-0.50$ & $0.35-0.40$ & 0.25 \\
Mg (\% of DM) & $0.25-0.30$ & $0.25-0.30$ & 0.20 \\
Salt (\% of DM) & $0.40-0.50$ & $0.40-0.50$ & 0.25 \\
\hline
\end{tabular}

\section{Description of the study}

The present study began in January 2013, ended in April 2015, spanned eight kidding periods and involved a total of 32 PT goats. Of the 32 PT does, 12 were Alpine, 9 were Saanen and 11 were Saanen-Alpine cross-breds. One PT doe in this study gave birth in January/February 2013, 4 in April/May 2013, 5 in September/October 2013, 5 in January/February 2014, 4 in April/May 2014, 1 in September/October 2014, 4 in January/February

Table 2 Composition of the commercial concentrate mixes fed to the lactating and dry goats

\begin{tabular}{lll}
\hline Ingredient & $\begin{array}{l}\text { High and Low } \\
\text { Production Does }\end{array}$ & Dry Does \\
\hline Ground corn & $15 \%$ & $17 \%$ \\
Ground barley & $12.5 \%$ & $10 \%$ \\
Corn gluten meal & $12 \%$ & $15 \%$ \\
Soybean oil meal & $11.5 \%$ & $12 \%$ \\
Canola oil meal & $9.5 \%$ & \\
Dried citrus pulp & $7.2 \%$ & $1.4 \%$ \\
Palm oil & $7 \%$ & $5 \%$ \\
Wheat bran & $6.8 \%$ & $13 \%$ \\
Sunflower oil meal & $5.5 \%$ & $10 \%$ \\
Ground wheat & $5 \%$ & $1.8 \%$ \\
Protected fat & $2 \%$ & $3.5 \%$ \\
Cane molasses & $2 \%$ & $6.5 \%$ \\
Distillers dried grains & $2 \% \%$ & $2.8 \%$ \\
Calcium, phosphorus and salt & $2.7 \%$ & $1.7 \%$ \\
Buffers & & $0.3 \%$ \\
Micro minerals and vitamins & & \\
\hline
\end{tabular}

2015 and 8 in April/May 2015. All the goats included in this study were dry (non-lactating) goats.

The prevalence of PT in the periods of the study was $7.1 \%(38 / 352)$ in January/February 2013, $5.3 \%$ (22/415) in April/May 2013, 2.0 \% (7/356) in September/October 2013, 6.9 \% (29/418) in January/February 2014, $4.3 \%$ (17/393) in April/May 2014, 1.6 \% (6/370) in September/ October 2014, 4.7 \% (19/405) in January/February 2015 and $4.6 \%$ (19/416) in April/May 2015.

\section{Inclusion criteria}

Any pregnant doe in the dry doe pen that refused to eat when fresh feed (concentrate) was offered (4 times during a $24 \mathrm{~h}$ period) was considered to be a PT suspect and her blood BHBA value was determined using an electronic on-farm test ${ }^{1}$. If this value was found to be $3 \mathrm{mmol} / \mathrm{L}$, or greater, she was considered a PT doe and handled accordingly. This inexpensive method of assessing BHBA status has recently been validated [10]. Anorectic goats with BHBA values lower than $3 \mathrm{mmol} / \mathrm{L}$ were treated with oral electrolytes (70\% glucose, $15 \%$ sodium chloride and $12 \%$ sodium bicarbonate, dissolved in $1.5 \mathrm{~L}$ of water) and propylene glycol $(50 \mathrm{ml})$ and rechecked in a daily basis until they resumed eating or developed a BHBA value in excess of $3.0 \mathrm{mmol} / \mathrm{L}$.

At the time that each PT doe was enrolled in this study, a physical examination was performed and clinical signs (of disease) and vital signs (rectal temperature, heart rate, respiratory rate and ruminal motility) were determined and recorded. In addition, a blood sample was obtained from the jugular vein with a 20-gauge needle using a $1 \mathrm{~mL}$ disposable syringe (rinsed with heparin sodium, 5000 IU $/ \mathrm{ml}^{2}$ ) and the following parameters were measured on the farm, 2 minutes maximal after blood collection using a portable analyzer ${ }^{3}$ : ions $\left(\mathrm{Na}^{+}, \mathrm{K}^{+}, \mathrm{Cl}^{-}\right.$and $\left.\mathrm{HCO}^{-}\right)$, glucose, $\mathrm{pH}, \mathrm{BE}, \mathrm{pCO} 2$ and $\mathrm{BUN}$. Urine was collected from 17 PT goats, when the goat was approached to perform the physical exam and complete urinalyses ${ }^{4}$ were performed.

Of the 32 goats included in the study, kidding was induced in 22 does by intramuscular injection of dexamethasone $^{5}$ (1 mg/10 Kg BW), and dexcloprostenol ${ }^{6}$ $(125 \mu \mathrm{l})$. A caesarian surgery was performed in the other 10 does.

\section{Statistical analysis}

A two-tailed $t$ test for independent samples [11] was used to compare the mean values of the data obtained from goats that died with goats that survived.

The probability of survival of the PT goats was analysed by logistic regression with the PROG LOGISTIC ${ }^{\bullet}$ from $\mathrm{SAS}^{7}$, with a model that included the effect of the analysed parameters (BHBA, pH, Glucose, $\mathrm{K}^{+}, \mathrm{pCO}_{2}, \mathrm{HCO}_{3}^{-}, \mathrm{BE}$, $\mathrm{Na}^{+}, \mathrm{Cl}^{-}$and $\mathrm{BUN}$ ) individually and as covariables. 
The values of these parameters were submitted to an analysis of variance with the PROC GLM ${ }^{\star}$ from SAS with a linear model that only includes the effect of death/survival. After that, the least square means of the different parameters were estimated.

In order to test the association between (1) the occurrence of a clinical signs that were observed in a patient (i.e., polypnea, swollen limbs, anorexia with absence of ruminal motility, recumbency, neurologic signs, and drooped ears) and (2) the death or survival of a patient, (3) number of foetuses alive after inducing the kidding versus caesarian surgery, (4) urine analysis (aciduria) the chi-square test and the Fisher's Exact Test were used, with the PROC FREQ ${ }^{\circledR}$ from SAS.

\section{Results}

In the present study, the case fatality rate was $75 \%(24 / 32)$. Among the goats that were submitted for caesarian surgery, the case fatality rate was $100 \%(10 / 10)$ and in those where kidding was induced, the case fatality rate was $64 \%(14 / 22)$.

The 22 goats in which parturition was induced gave birth to a total of 50 kids, 48 were alive (96\%). From these, three goats died before they gave birth. The 10 goats in which a caesarian surgery was performed gave birth to a total of 26 kids, 20 were alive $(77 \%)$. This difference is statistically significant $(p<0.01)$.

A comparison of the median ages, BCS, number of fetuses and vital signs of the 24 dead goats and the 8 surviving goats are presented (Table 3 ). Ruminal motility was significantly more likely to be present in surviving does that in the does that died $(p<0.001)$.

Table 3 Ages, BCS, number of Foetuses, vital signs in the 24 dead goats and in the 8 surviving goats

\begin{tabular}{|c|c|c|c|}
\hline \multirow{2}{*}{$\begin{array}{l}\text { Parameter } \\
\text { studied }\end{array}$} & \multirow{2}{*}{$\begin{array}{l}\text { Dead Goats } \\
\text { Median (Range) }\end{array}$} & \multirow{2}{*}{$\begin{array}{l}\text { Surviving goats } \\
\text { Median (Range) }\end{array}$} & \multirow{2}{*}{$\begin{array}{l}\text { Control goats } \\
(n=22)\end{array}$} \\
\hline & & & \\
\hline Age (years) & $4(2-8)$ & $4(2-6)$ & $2-6^{a}$ \\
\hline $\mathrm{BCS}$ & $3.0(2-3.5)$ & $3.0(2.5-3.5)$ & $2.5-2.75^{b}$ \\
\hline $\begin{array}{l}\text { Number of } \\
\text { foetuses }\end{array}$ & $3(2-4)$ & $3(2-3)$ & $2-3^{a}$ \\
\hline $\begin{array}{l}\text { Rectal } \\
\text { Temperature }{ }^{\circ} \mathrm{C} \text { ) }\end{array}$ & $38.6(37-39.2)$ & $38.9(38.7-39.2)$ & $37.7-39.8^{\mathrm{a}}$ \\
\hline Heart rate & $114(60-172)$ & $132(100-152)$ & $72-154^{a}$ \\
\hline \multirow[t]{2}{*}{ Respiratory rate } & $48(28-100)$ & $48(32-108)$ & $24-64^{a}$ \\
\hline & $\begin{array}{l}\text { Dead Goats } \\
\text { Frequency }\end{array}$ & $\begin{array}{l}\text { Surviving goats } \\
\text { Frequency }\end{array}$ & \\
\hline $\begin{array}{l}\text { Rumen motility } \\
Y=Y e s / N=\text { No }\end{array}$ & Y-4 N-16 & $\mathrm{Y}-5^{*} \mathrm{~N}-1$ & $\begin{array}{l}\text { Y-1-2 contractions } \\
\text { per minute }\end{array}$ \\
\hline
\end{tabular}

$B C S$ body condition score, NA non applicable

a Lima et al. [4]

${ }^{\mathrm{b}}$ Smith $\mathrm{M}$ and Sherman D [1]

${ }^{*} p<0.001$
The following clinical signs were observed in the 32 PT does of this study:

Polypnea (88\%, 28/32), swollen limbs (78 \%, 25/32), anorexia with absence of ruminal motility (69 \%, 17/26), sternal recumbency, but able to rise upon stimulation (66 \%, 21/32), and neurological signs, such as "star gazing" or opisthotonos $(9 \%, 3 / 32)$, and drooping ears $(9 \%, 3 / 32)$. These results are summarized in Fig. 1 and for these there was a statistically significant difference in survival rates in goats with anorexia with absence of ruminal motility $(p<0.01)$ and recumbency $(p<0.01)$ (Figs. 2 and 3, respectively).

Urine samples were collected from 17 PT goats and complete urinalysis performed. Ketonuria and aciduria were the only abnormalities detected and both were present in 13 does, while ketonuria (without aciduria) was present in 4 does. In this study the threshold for aciduria was observed in a goat with a blood $\mathrm{pH}$ of 7.35. From the 24 goats that died, urine was collected in 13 and 12 (92\%) of these showed aciduria and ketonuria and one showed only ketonuria (8\%). Urinalysis was performed in four of the eight surviving goats. Three of them showed ketonuria (75\%) and one showed aciduria and ketonuria (25\%). The difference in the occurrence of aciduria between the goats that died and the ones that survived is statistically significant $(p<0.05)$.

The blood chemistry values from the 24 dead goats and from the 8 surviving goats are shown in Table 4 . Median blood levels of $\mathrm{K}^{+}(p<0.005), \mathrm{pH} \quad(p<0.005)$, $\mathrm{HCO}_{3}^{-}(p<0.001), \mathrm{BE}(p<0.001)$, and $\mathrm{pCO}_{2}(p<0.005)$ were significantly lower in the goats that died than in the surviving goats. The probability of survival of the PT goats was analysed by logistic regression and the prognostic values of the blood $\mathrm{pH}, \mathrm{HCO}_{3}^{-}, \mathrm{BE}, \mathrm{K}^{+}$and $\mathrm{pCO}_{2}$ and for the case fatality rate in PT goats are shown (Figs. 4, 5, 6, 7 and 8 respectively).

As seen in Fig. 4, at a $\mathrm{pH}$ of 6.99, the probability that a PT goat doesn't survive is $99 \%$. This probability decreases to 75,50 and $25 \%$ at values of $7.26,7.35$ and 7.44 respectively. The equation used to build this curve was the following:

$$
P(y=1)=\frac{e^{87.099-11.837 x}}{1+e^{87.099-11.837 x}}
$$

$\mathrm{y}=$ probability of dying and $\mathrm{x}=$ blood $\mathrm{pH}$

It is possible to observe in Fig. 5 that the probability that a PT goat dies when the blood levels of $\mathrm{HCO}_{3}^{-}$are $3 \mathrm{mmol} / \mathrm{L}$ is $98 \%$. This probability decreases to 75,50 and $25 \%$ at blood levels of 15, 20, $25 \mathrm{mmol} / \mathrm{L}$, respectively. The equation used to build this curve was the following: 


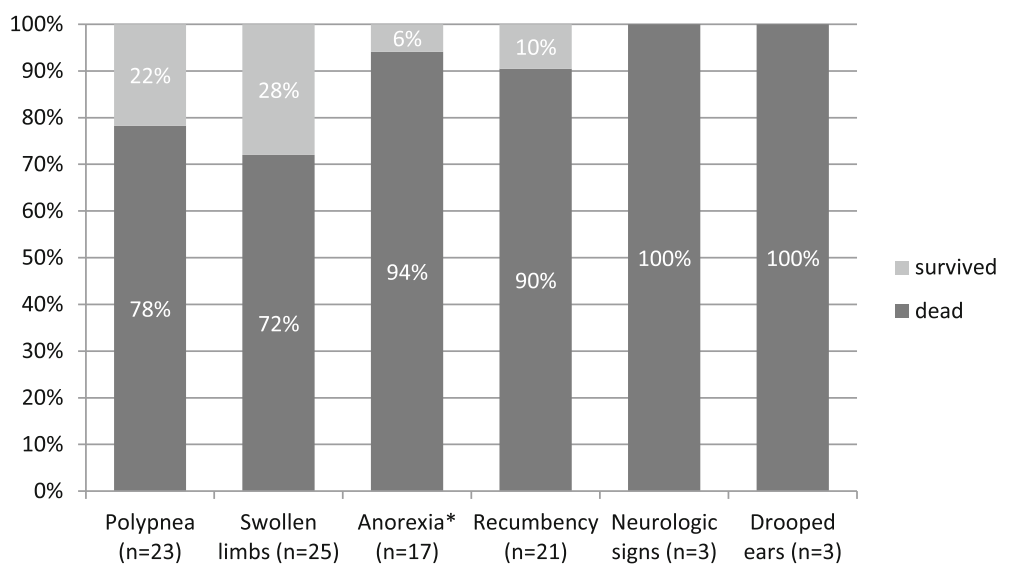

Fig. 1 Percentage of the goats that died and survived in function of the most observed clinical signs. The total number of animals that presented each clinical sign is shown

$$
P(y=1)=\frac{e^{4.597-0.240 x}}{1+e^{4.597-0.240 x}}
$$

$\mathrm{y}=$ probability of dying and $\mathrm{x}=$ blood $\mathrm{HCO}_{3}^{-}$

In Fig. 6, it is possible to observe that when the $\mathrm{BE}$ is $-30 \mathrm{mmol} / \mathrm{L}$, the probability that a PT goat dies is $99 \%$. This probability decreases to 75,50 and $25 \%$ at values of $-12,-6$ and $0 \mathrm{mmol} / \mathrm{L}$ respectively. The equation used to build this curve was the following:

$$
P(y=1)=\frac{e^{-1.207-0.186 x}}{1+e^{-1.207-0.186 x}}
$$

$\mathrm{y}=$ probability of dying and $\mathrm{x}=$ blood $\mathrm{BE}$

When $\mathrm{K}^{+}$is $2 \mathrm{mmol} / \mathrm{L}$ or less the probability that the PT goat will not survive is $99 \%$. This probability decreases to 75,50 and $25 \%$ at values of $\leq 3.3, \leq 3.6$ and $\leq 4 \mathrm{mmol} / \mathrm{L}$ respectively, (Fig. 7). The equation used to build this curve was the following:

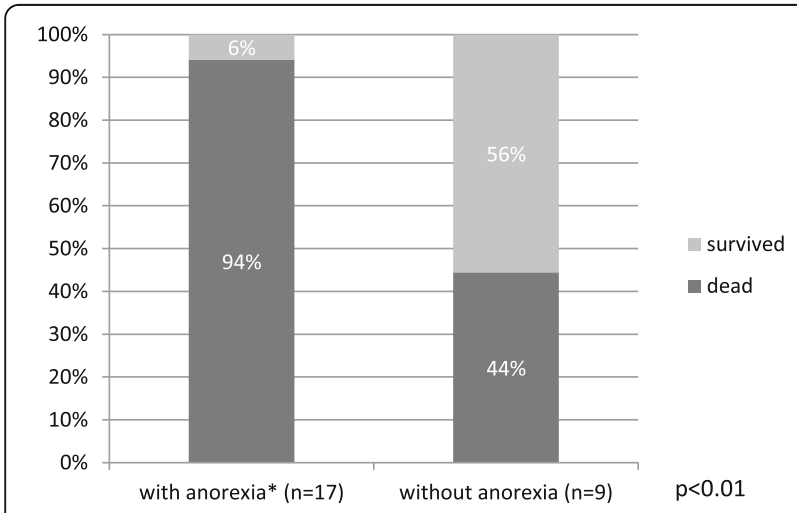

Fig. 2 Comparison between the goats that died and survived with and without anorexia. The total number of animals is shown

$$
P(y=1)=\frac{e^{11.676+3.213 x}}{1+e^{11.676+3.213 x}}
$$

$\mathrm{y}=$ probability of dying and $\mathrm{x}=$ blood $\mathrm{K}^{+}$

When pCO2 is $\leq 18 \mathrm{mmHg}$, the probability of death of the PT goat is $95 \%$. This probability decreases to 75,50 and $25 \%$ at values of $\geq 29, \geq 36$ and $\geq 43 \mathrm{mmHg}$ respectively (Fig. 8). The equation used to build this curve was the following:

$$
P(y=1)=\frac{e^{-5.962+0.166 x}}{1+e^{-5.962+0.166 x}}
$$

$\mathrm{y}=$ probability of dying and $\mathrm{x}=$ blood $\mathrm{pCO}_{2}$

\section{Discussion}

When dealing with a goat with clinical signs of PT in the last days of gestation in practice, a clinician must quickly take some decisions about what should be done. Since only patients in the very early stages of PT respond well to medical treatments [4], the clinician

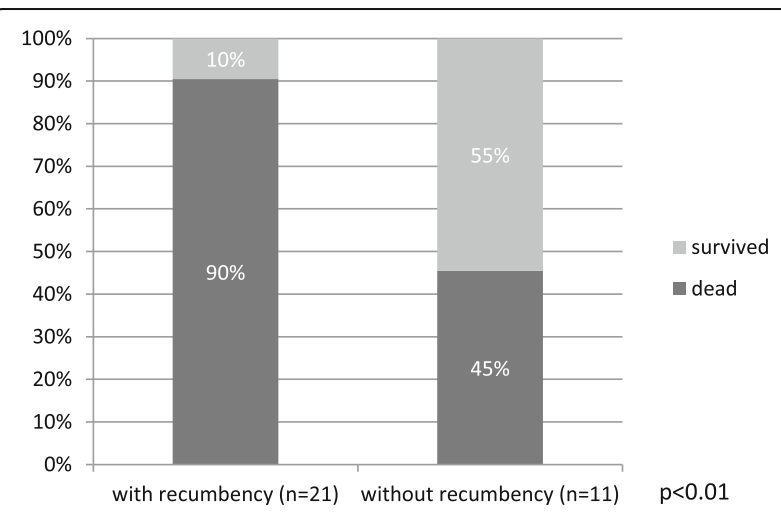

Fig. 3 Comparison between the goats that died and survived with and without recumbency. The total number of animals is shown 
Table 4 Blood chemistry values from the 24 dead goats and from the 8 surviving goats

\begin{tabular}{llll}
\hline $\begin{array}{l}\text { Parameter } \\
\text { Measured }\end{array}$ & $\begin{array}{l}\text { Dead goats } \\
\text { Median (Range) }\end{array}$ & $\begin{array}{l}\text { Surviving goats } \\
\text { Median (Range) }\end{array}$ & $\begin{array}{l}\text { Control Goats } \\
(n=22)\end{array}$ \\
\hline $\mathrm{Na}^{+}(\mathrm{mmol} / \mathrm{L})$ & $139(123-145$ & $142(138-145)$ & $128-145^{\mathrm{a}}$ \\
$\mathrm{K}^{+}(\mathrm{mmol} / \mathrm{L}$ & $2.7(1.8-3.8$ & $3.7^{*}(3.5-4.3)$ & $3.3-4.3^{\mathrm{a}}$ \\
$\mathrm{Cl}^{-}(\mathrm{mmol} / \mathrm{L})$ & $110(103-121$ & $109(96-111)$ & $102-112^{\mathrm{a}}$ \\
$\mathrm{GluCose}(\mathrm{mmol} / \mathrm{L}$ & $2.1(1.1-5.8)$ & $1.9(1.7-2.8)$ & $2.1-3.4^{\mathrm{a}}$ \\
$\mathrm{pH}$ & $7.13(6.84-7.45$ & $7.39^{*}(7.30-7.43)$ & $7.31-7.45^{\mathrm{a}}$ \\
$\mathrm{HCO}_{3}^{-}(\mathrm{mmol} / \mathrm{L})$ & $8.3(3.3-21$ & $21^{* *}(14-35$ & $19-29^{\mathrm{a}}$ \\
$\mathrm{BE}(\mathrm{mmol} / \mathrm{L})$ & $\mathrm{BE}(\mathrm{mmol} / \mathrm{L})$ & $-4.5^{* *}(-12-+10)$ & $-0.8-+4^{\mathrm{a}}$ \\
$\mathrm{PCO}(\mathrm{mmHg}$ & $26(16-42)$ & $33^{*}(28-56)$ & $31-44^{\mathrm{a}}$ \\
$\mathrm{BUN}(\mathrm{mmol} / \mathrm{L})$ & $6.1(2.9-17.6)$ & $4.0(2.2-7.2)$ & $1-3.8^{\mathrm{a}}$ \\
$\mathrm{BHBA}(\mathrm{mmol} / \mathrm{L})$ & $6.5(3.8-8.6)$ & $6.0(3.2-10.6)$ & $<0.7^{\mathrm{b}}$
\end{tabular}

${ }^{*} p<0.005$

${ }^{* *} p<0.001$

a Lima et al. [4]

${ }^{\mathrm{b} C h r i s t i a n ~ J A ~ a n d ~ P u g h ~ D G ~[19] ~}$

must first decide if the option should be pharmaceutical induction of kidding or caesarian surgery. Goats with PT have a high mortality and their condition can deteriorate quickly [4]. It has been our experience that a good strategy to minimize the economic losses caused by PT is to focus on offspring survival rates rather than on the doe. The criterion used to decide whether to induce parturition or perform a caesarian surgery was the blood $\mathrm{pH}$ value, since a decrease in the blood $\mathrm{pH}$ has a negative impact on the prognosis of PT goats as it was shown in a previous study [4]. When the $\mathrm{pH}$ of the PT goat at the first observation was below 7.15, a caesarian surgery was performed; when the $\mathrm{pH}$ was above 7.15 , induction of parturition was the option utilized.

It has been reported in sheep that very small changes in maternal $\mathrm{pH}$ may cause significant derangement is foetal function and outcome [12]. Since the percentage of the kids alive after caesarian surgery was lower (77 \%) than those where parturition was induced (96\%) we hypothesised that the decreased rate of survival of the foetuses is also influenced by the lower blood $\mathrm{pH}$.

Deciding between treatment options in affected animals should be based on the economic value of the mother and offspring, as well as on the clinical signs and certain haematological parameters.

In our study the clinical findings most indicative of a poor prognosis are 1) anorexia with absence of ruminal motility and recumbency (Figs. 2 and 3). We have reported previously [4] and therefore is our experience that drooped ears and nervous signs are associated with a very unfavorable outcome. However in this study there was not a statistically significant association between these two signs and the prognosis. This may be explained by the small size of the sample.

In the present study, the case fatality rate was not influenced by factors such as, age, number of fetuses, $\mathrm{BCS}$, rectal temperature, heart rate or respiratory rate. However, both the surviving and the fatal PT cases had elevated heart and respiratory rates, which could reflect attempts by the animal to compensate for the increased abdominal volume and for the metabolic acidosis that was observed in most of the goats in this study $[2,4,5]$.

A recent study [13] tried to identify risk factors for developing $\mathrm{PT}$ in goats during the last month of gestation based on their blood BHBA values.

All PT goats in this study had BHBA levels above $3 \mathrm{mmol} / \mathrm{L}$. The difference in BHBA levels $(6.5 \mathrm{mmol} / \mathrm{L}$ vs $6.0 \mathrm{mmol} / \mathrm{L}$ ) between the PT goats that died and those that survived was not statistically significant, indicating that BHBA values have little prognostic value for $\mathrm{PT}$ in goats.

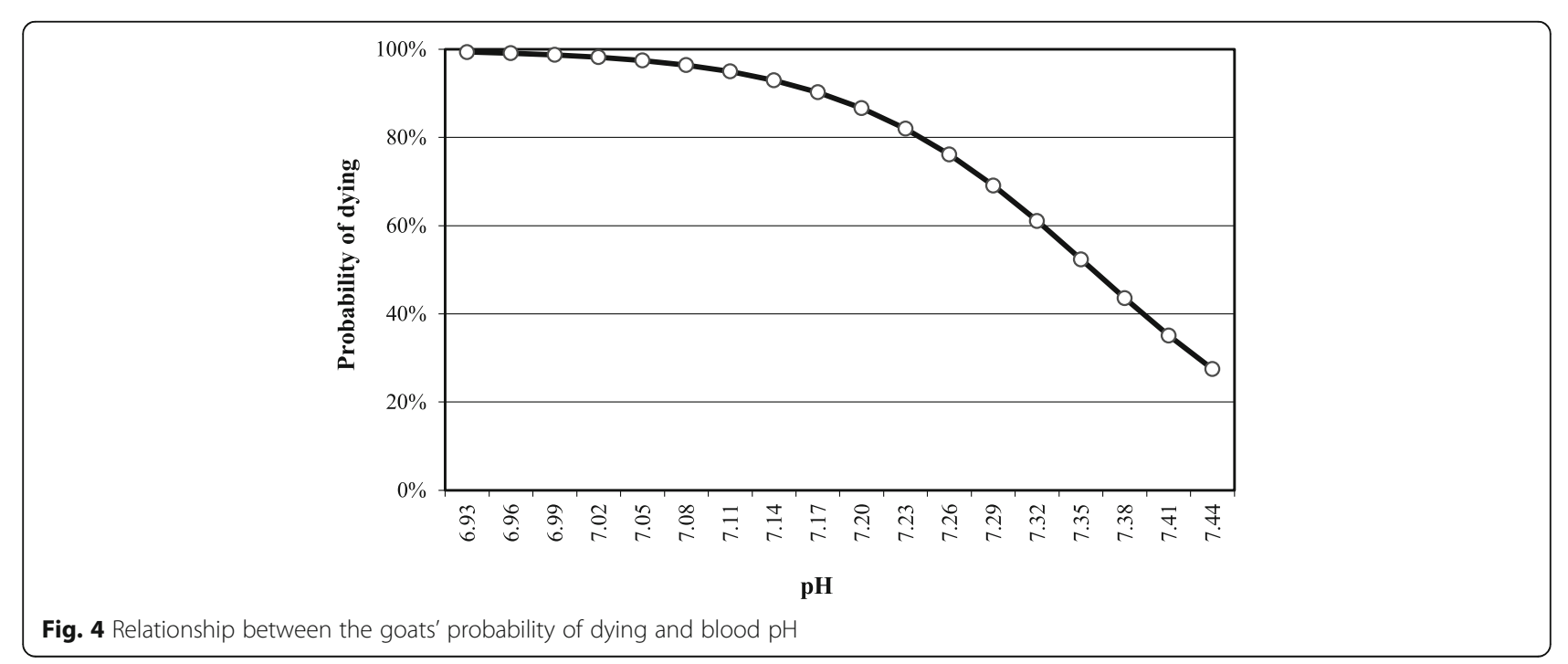




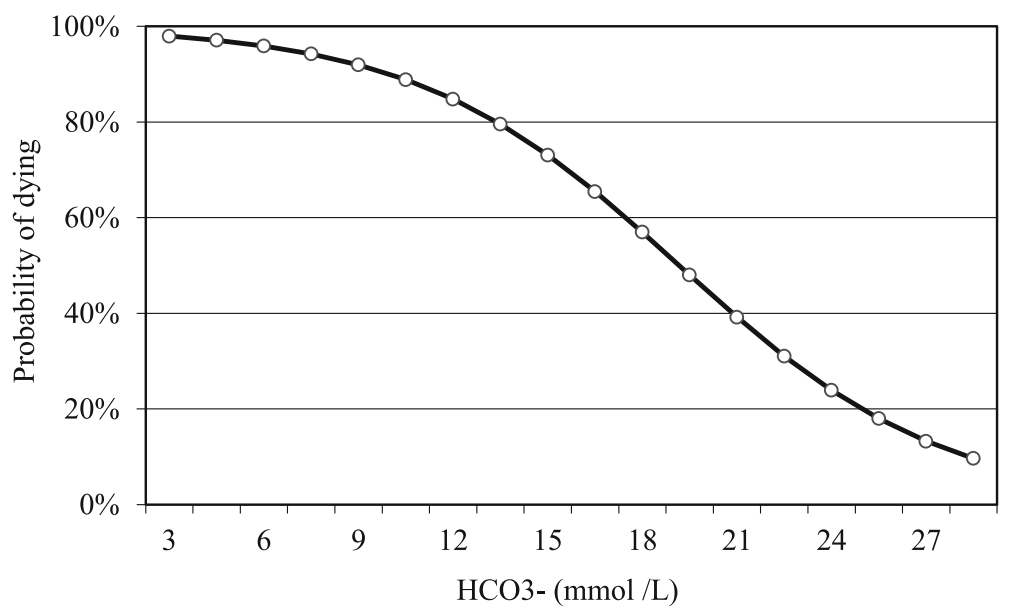

Fig. 5 Relationship between the goat's probability of dying and blood $\mathrm{HCO}_{3}^{-}$

In this study we have shown statistically significant differences in blood levels of $\mathrm{pH}, \mathrm{K}^{+}, \mathrm{HCO}_{3}^{-}, \mathrm{BE}$, and $\mathrm{pCO}_{2}$, between the goats that survived and the ones that died, so these parameters can be used as valid prognostic indicators.

Maternal blood glucose levels can be used as sign of the viability of the foetuses [14-16] Hyperglycaemia in the dam was shown to be associated with fetal death [14-16]. In our study the levels of glycaemia were not elevated in both groups of goats.

It would be useful to establish a correlation between some haematological parameters and clinical signs of PT in goats, using clinical signs such as behavior pattern, ability to stand, nervous signs and drooping ears, as examples. In future studies we will try to explore this area.

During the clinical workup of a PT goat urine analysis is recommended. Unfortunately it is harder to obtain urine samples from does that from cows or ewes.
However, a goat, that has been recumbent will often urinate when encouraged to stand [1]. Our results show that the difference in the occurrence of aciduria between the goats that died and the ones that survived is statistically significant $(p<0.05)$ and that goats with ketonuria had a blood BHBA above $3.8 \mathrm{mmol} / \mathrm{L}$. It would be a laudable goal for future work to identify at which levels of BHBA leads to clinically detectable ketonuria in these animals.

According to previous studies, a good predictor of impending death in a PT goat is the blood $\mathrm{pH}$ value [4]. However, in our experience, in PT goats, the $\mathrm{pH}$ can fall very rapidly, and the physical condition of these goats can also deteriorate very rapidly. Because of this, a timely decision has to be made as to whether to induce kidding with pharmaceuticals or to perform a caesarian surgery. The case fatality rate in these 10 PT does was $100 \%$. However we were able to remove a total of 26 kids, 20 of which were alive (77\%) after performing the surgery.

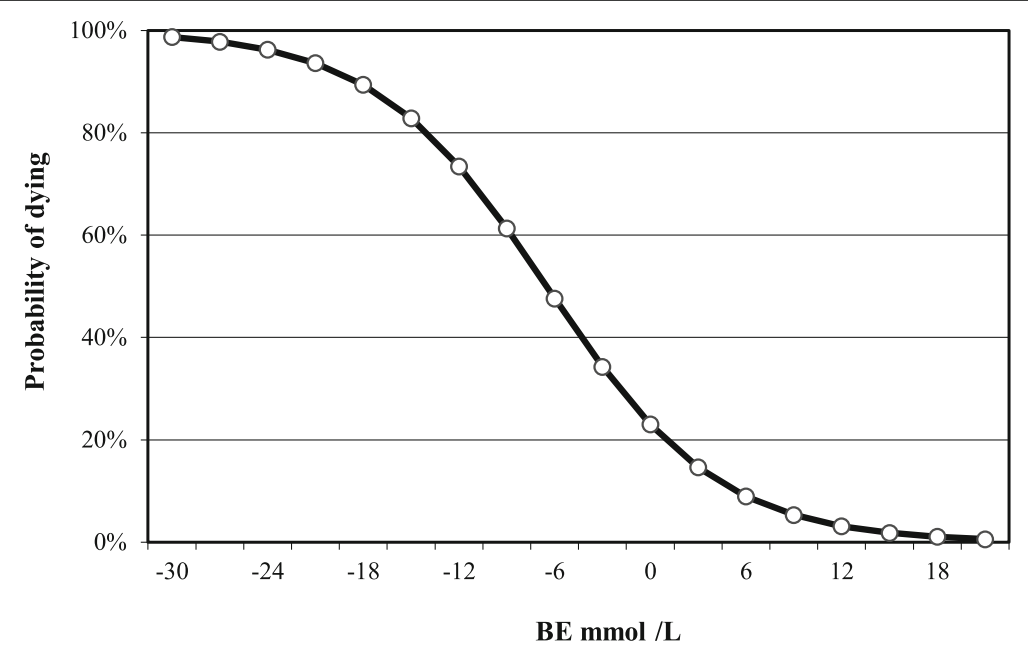

Fig. 6 Relationship between the goats' probability of dying and blood BE 


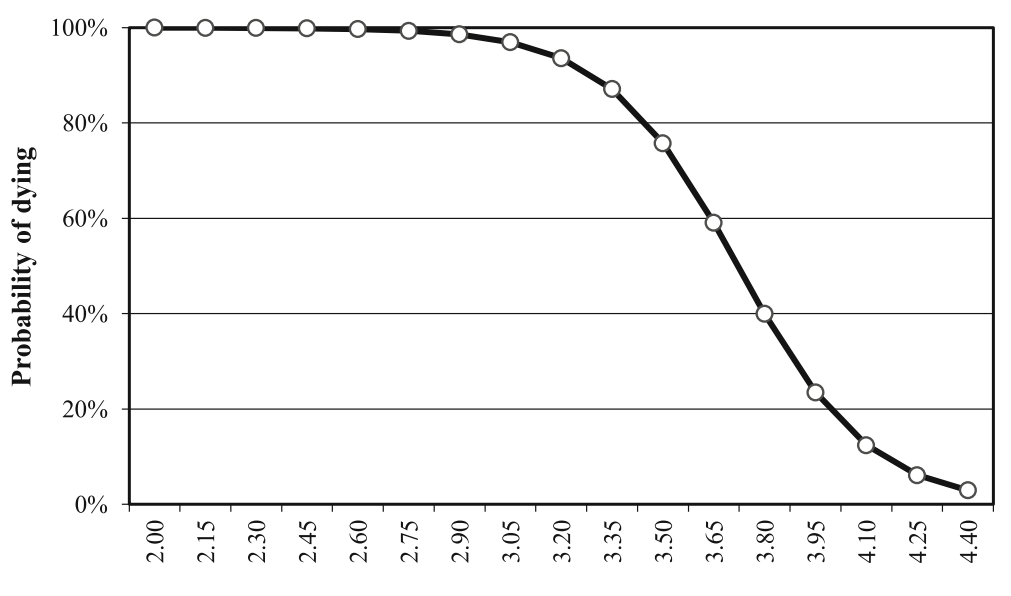

$\mathrm{K}^{+}(\mathbf{m m o l} / \mathbf{L})$

Fig. 7 Relationship between the goat's probability of dying and blood $\mathrm{K}^{+}$

Hypokalaemia has been reported as a consistent feature of naturally occurring PT in goats $[4,15]$ and it can be considered a good indicator of prognosis. As shown in the results the blood levels of $\mathrm{K}^{+}$were significantly lower in the goats that died. It has been shown that in human patients with ketoacidosis and ketonuria, that there is a marked loss of $\mathrm{K}^{+}$in the urine leading to hypokalaemia [17] . It seems logical that hypokalemia observed in PT goats in the present study could have resulted for the same mechanisms that caused hypokalaemia in human patients. On the other hand, goats with PT in the current study had a lower feed intake, which might have contributed to this hypokalaemia.

Due to the fact that mortality in PT goats often exceeds $80 \%$ in untreated animals [5] and that the efficacy of several protocol treatments is not very effective [4] the best strategy to deal with this disease is prevention. However, in our experience it is not very easy to prevent this problem.
Goats from the improved breeds Saanen and Alpine have a great prolificacy and tend to accumulate substantial amounts of fat in their abdominal cavity $[1,5]$. This reduces space availability for ruminal expansion, therefore these animals are unable to consume sufficient quantities of feedstuffs to satisfy their energy requirements [2]. We have been trying some strategies to decrease the prevalence of PT in this farm.

One strategy is to group goats according to the level of their milk production in order to avoid overfeeding of the lower production goats. The importance of increased exercise to prevent PT in pregnant sheep has been reported $[15,18]$. Forced exercise in pregnant sheep was associated with reduced blood concentration of free fatty acids, presumably resulting from increased utilization [18]. In the past we have provided additional pen space to goats in the last month of gestation in order to encourage them to exercise more. The results were not very encouraging.

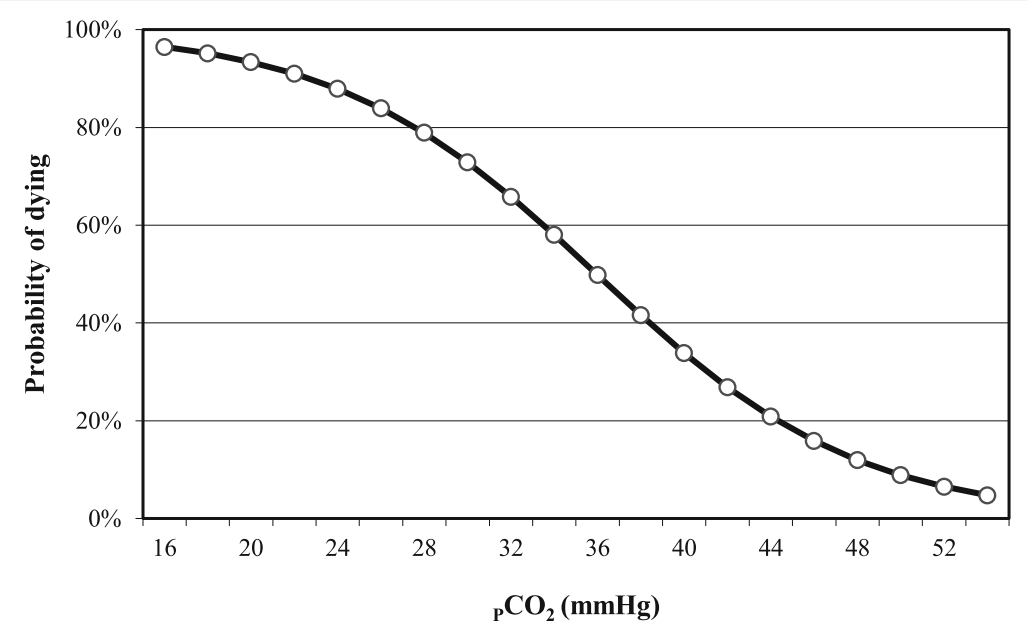

Fig. 8 Relationship between the goat's probability of dying and blood $\mathrm{pCO}_{2}$ 


\section{Conclusions}

The clinical signs most indicative of a poor prognosis are anorexia with absence of ruminal motility and recumbency. Among the blood parameters to be considered, $\mathrm{K}^{+}$and metabolic acidosis are the most relevant. The authors are aware that the findings of this study are based on a relatively small sample size and may be subjected to future revisions, as more case studies become available for analysis. A clinician facing PT in a goat in a commercial farm often faces challenges including availability of proper treatment facilities and the opportunity to perform sequential diagnostic blood testing. However, the clinician still needs to make timely decisions concerning the management of individual PT cases. Because of the high case fatality rate associated with PT, an early decision (induction of kidding or caesarian surgery) is essential to potentially facilitate the production of live kids.

\section{Endnotes}

${ }^{1}$ Precision Xceed, Abbott, UK.

${ }^{2}$ B. Braun Medical Lda, Queluz de Baixo).

${ }^{3}$ i-Stat, Sensor Devices Incorporated, Waukesha, WI; USA.

${ }^{4}$ Aution Sticks, Arkray Europe, Netherlands.

${ }^{5}$ Vetacort $^{\oplus}$, Vetoquinol, Barcarena, Portugal.

${ }^{6}$ Gestavet-Prost ${ }^{\oplus}$, Hipra, Lisboa, Portugal.

${ }^{7}$ SAS Institute, Heidelberg, Germany.

\section{Abbreviations}

BCS: Body condition score; BE: Base excess; BHBA: Beta-hydroxybutyric acid; BUN: Blood urea nitrogen; PT: Pregnancy toxaemia; TMR: Total mixed ration

\section{Acknowledgments}

The authors wish to thank Mr. Antonio Barao for allowing the authors to carry out this study on his farm.

\section{Funding}

The present study received financial support from CIISA (Project UID/CVT/00276/ 2013), Faculdade de Medicina Veterinaria, Universidade de Lisboa, Portugal).

\section{Availability of data and materials}

The datasets during and/or analysed during the current study available from the corresponding author on reasonable request.

\section{Authors' contributions}

$M L$ and JS designed the experiment and did most of the field work (physical examinations, blood collection). NC performed the statistical analysis. LL and $\mathrm{CH}$ helped to draft and to revise the manuscript. RP identified the sick goats and helped with the field work. All authors read and approved the final version of the manuscript.

\section{Competing interests}

The authors declare that they have no competing interests.

Consent for publication

Not applicable.

\section{Ethics approval}

All the experimental procedures (handling, blood sampling, and caesarean section when applicable) were performed so as to minimize the stress and discomfort experienced by the animals upon approval by the University Ethics Committee (Comissão de Ética e Bem-Estar Animal da Faculdade de Medicina Veterinária). Since the study was done on a private farm with the consent of the owner, according to our rules, no protocol number was required or issued.

\section{Author details}

${ }^{1}$ Faculdade de Medicina Veterinária, Centro de Investigação Interdisciplinar em Sanidade Animal (CIISA), DC, Universidade de Lisboa, Polo Universitário da Ajuda, Lisbon 1300-477, Portugal. ${ }^{2}$ INIAV, EUVG, CIISA, Lisbon, Portugal.

${ }^{3}$ Barão e Barão Lda, Coutada Velha, Benavente 2130-010, Portugal. ${ }^{4}$ School of Veterinary Medicine, University of California, Davis, CA 95616, USA.

Received: 17 May 2016 Accepted: 15 October 2016

Published online: 24 October 2016

\section{References}

1. Smith M, Sherman D. Nutrition and metabolic diseases. In: Smith M, Sherman D, editors. Goat Medicine. 2nd ed. Ames: Wiley-Blackwell; 2009. p. 773-8.

2. Navarre CB, Baird AN, Pugh DG. Diseases of the Gastrointestinal system. In: Pugh DG, Baird AN, editors. Sheep and Goat Medicine. Philadelphia: Saunders Elsevier; 2012. p. 71-103.

3. Radostits OM, Gay CC, Hinchcliff KW, Constable PD. General systemic states and pregnancy toxaemia in sheep. In: Radostits OM, Gay CC, Hinchcliff KW, Constable PD, editors. Veterinary Medicine. 10th ed. Philadelphia: WB Saunders Co; 2007. p. 1668-71.

4. Lima MS, Pascoal RA, Stilwell GT, Hjerpe CA. Clinical Findings, Blood Chemistry Values, and Epidemiologic Data Obtained from Dairy Goats with Pregnancy Toxemia (PT). Bov Pract. 2012;46(2):102-10.

5. Rook JS. Pregnancy toxemia of ewes, does and beef cows. Vet Clin North Am, Food Anim Pract. 2000;16:293-317.

6. Scott PR, Sargison ND, Penny CD, Pirie RS, Kelly JM. Cerebrospinal fluid and plasma glucose concentrations of ovine pregnancy toxaemia cases, inappetant ewes and normal ewes during late gestation. Br Vet J. 1995;151:39-44.

7. Cantley CEL, Ford CM, Heath MF. Serum fructosamine in ovine pregnancy toxemia: a possible prognostic index. Vet Rec. 1991;128:525-6.

8. Sargison ND, Scott PR, Penny CD, Pirie RS, Kelly JM. Plasma enzymes and metabolites as potential prognostic indices of ovine pregnancy toxaemia-a preliminary study. Br Vet J. 1994;150:271-7.

9. Scott PR, Woodman MP. An outbreak of pregnancy toxaemia in a flock of Scottish blackface sheep. Vet Record. 1993;133:597-8.

10. Doré V, Dubuc J, Bélanger AM, Buczinski S. Evaluation of the accuracy of an electronic on-farm test to quantify $\beta$-hydroxybutyrate concentration in dairy goats. J Dairy Sci. 2013;96:1-3.

11. Snedecor GW, Cochran WG. The comparison of two samples. In: Statistical Methods. 7th ed. lowa: lowa University Press; 1980. p. 83-106.

12. Omo-Aghoja L. Maternal and Fetal Acid-base Chemistry. A major determinant of perinatal outcome. Annals Med Health Res. 2014;4:8-17.

13. Doré V, Dubuc J, Bélanger AM, Buczinski S. Definiton of prepartum Hyperketonemia in dairy goats. J Dairy Sci. 2015;98:4535-43.

14. Wastney ME, Wolf JR, Bickerstafle R. Glucose turnover and hepatocyte glucose production of starved and toxaemic pregnant sheep. Aust J Biol Sci. 1983:36:271-84

15. Marteniuk JV, Herdt TH. Pregnancy toxemia and ketosis of ewes and does. Vet Clin North Am, Food Animal Practice. 1988:4:307-15.

16. Lima MS, Pascoal RA, Stilwell GT. Glycemia as sign of the viability of the foetuses in the last days of gestation in dairy goats with pregnancy toxemia. Ir Vet J. 2012;65(1):1. doi:10.1186/2046-0481-65-1.

17. Rose BT, Post TW. Hypokalemia. In: Clinical Physiology of Acid-base and Electrolyte Disorders. 5th ed. McGraw-Hill: Medical Publishing Division; 2001. p. 836-87.

18. Bulgin MS. Pregnancy toxemia -an in depth review. Wool \& Wattles. 2005; 33(1):9-10.

19. Christian JA, Pugh DG. Reference values and conversions. In: Pugh DG, editor. Sheep and Goat Medicine. Philadelphia: Saunders Elsevier; 2012. p. 596-600. 